\title{
RESEARCH
}

\section{Great Lakes Management: Ecological Factors}

W. C. SONZOGNI'

Great Lakes Environmental Research Laboratory

National Oceanic and Atmospheric Administration

2300 Washtenaw Avenue

Ann Arbor, Michigan 48104

A. ROBERTSON

Office of Marine Pollution Assessment

National Oceanic and Atmospheric Administration

Rockville, Maryland 20852

A. M. BEETON

Great Lakes and Marine Waters Center

University of Michigan

Ann Arbor, Michigan 48109
ABSTRACT / Although attempts to improve the quality of the Great Lakes generally focus on chemical pollution, other factors are important and should be considered Ecological factors, such as invasion of the lakes by foreign species, habitat changes, overfishing, and random variations in organism populations, are especially influential. Lack of appreciation of the significance of ecological factors stems partly from the inappropriate application of the concept of eutrophication to the Great Lakes. Emphasis on ecological factors is not intended to diminish the seriousness of pollution, but rather to point out that more cost-effective management, as well as more realistic expectations of management efforts by the public, should result from an ecosystem management approach in which ecological factors are carefully considered.
Factors other than chemical pollutants affect the water quality of lakes, or at least the public's perception of quality. Among the most important influences are variations in climate or weather (Sonzogni 1976), fluctuations in water levels and other aspects of water quantity (Morgan and Sonzogni 1980), and both natural and man-induced changes in the ecosystem arising from causes other than chemical pollution. For want of a better term, the latter are referred to as ecological factors. The purpose of this paper is to illustrate how these ecological factors affect the quality of lakes. In particular, the importance of recognizing how these factors may affect lake management, such as how they may delay or promote response to pollution control efforts, is discussed. The focus is on the North American Great Lakes, one of the largest and most valuable freshwater resources in the world and the subject of intense management (Figure 1). The management implications apply to lakes in general, however.

Ecological interrelationships are so complex it is often difficult to evaluate what has caused changes in the quality of a lake. This can lead to simplistic statements concerning the perceived causes of degradation. For example, there are many cases where chemical pollution is cited as the cause of poor fishing, when, in fact, the available evidence indicates other reasons for lack of a fish catch. As a result of such misconceptions, pollution control efforts may be undertaken for the wrong reasons or may focus on the wrong causes. Given the economic realities of today (high taxes, energy shortages,

KEY WORDS: Eutrophication; Fish; Plankton; Aquatic plants; Water quality; Mathematical modeling

${ }^{1}$ Present address: State Laboratory of Hygiene, 465 Henry Mall, University of Wisconsin, Madison, WI 53706. unemployment, inflation, etc.), such mislirected efforts must be avoided through wise and cost-effective management. Consequently, it is especially important at this time to recognize the importance of ecological factors in determining environmental quality.

This paper considers ecological factors from historical, current, and future perspectives. The eutrophication of the Great Lakes is reexamined, since the effect of this process on large lakes is often incorrectly perceived and its importance, relative to other influences (such as ecological factors) on quality of large lakes, often misrepresented. In addition, the status of mathematical models, which are having an increasingly influential role in lake management, are considered as a means of accounting quantitatively for ecological events. Finally, conclusions are drawn detailing the implications to management of recognizing the importance of ecological factors.

\section{Historical Perspectives}

The Great Lakes have undergone many striking changes in biology and chemistry over the past century. In Lake Erie, once abundant fish, such as the blue pike (Stizostedion vitreum glaucum), are now considered extinct. Other species that once made up an important part of the commercial fishery are of minor significance now. For example, the annual catch of the cisco or lake herring (Coregonus artedii), which once was as high as 22 million $\mathrm{kg}$, is presently less than $500 \mathrm{~kg}$. The Atlantic salmon (Salmo salar salar), which formerly ascended the tributaries of Lake Ontario, have disappeared entirely from the lake. In all of the Great Lakes, lake trout (Salvelinus fontinalis) have been virtually eliminated.

Major changes have also occurred in Lake Erie benthos. Forms associated with clean water environments have declined 


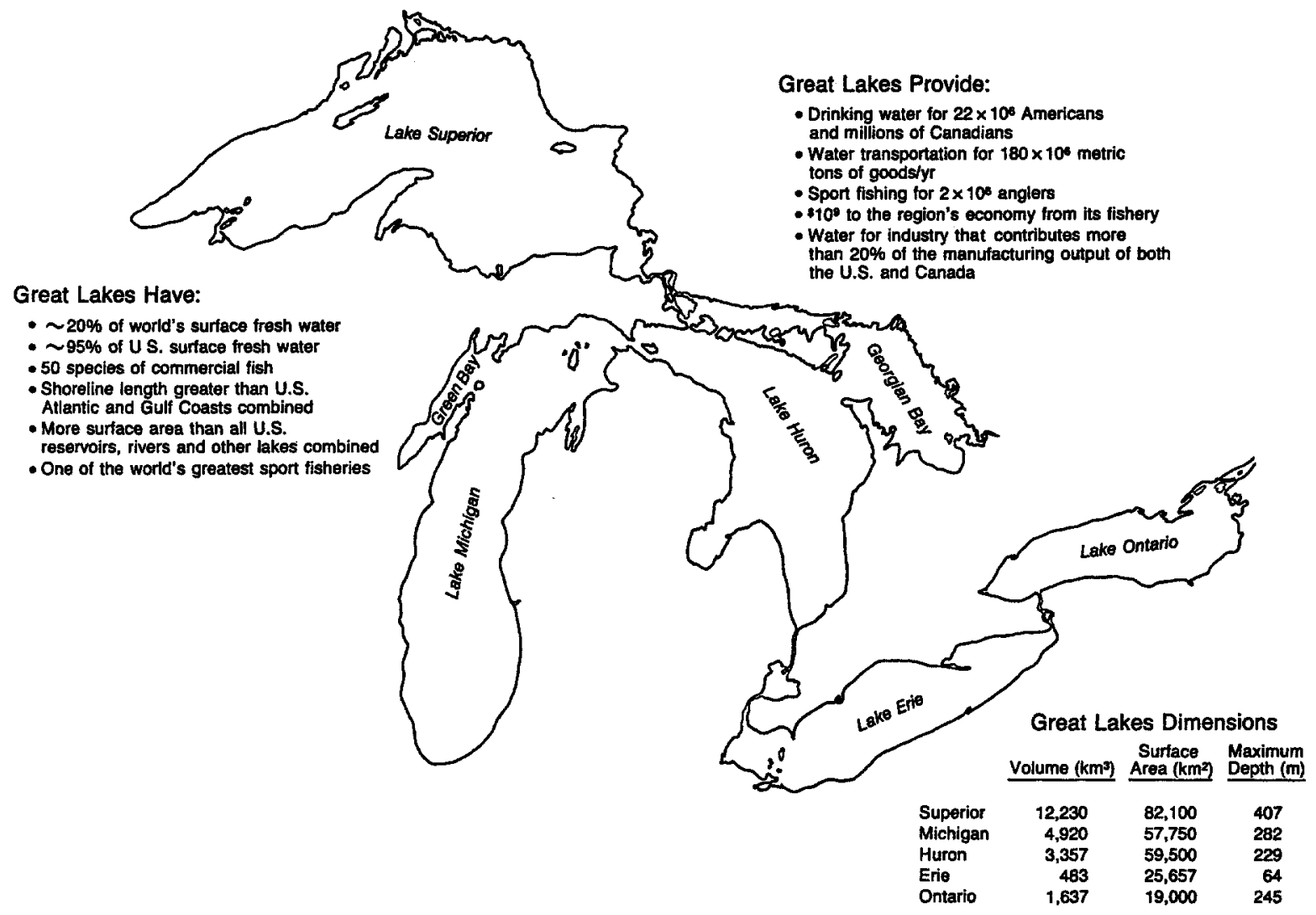

Figure 1. The North American Great Lakes, one of the world's largest and most valuable fresh water resources.

and have been replaced by pollution tolerant species (Beeton 1969). Planktonic algae have become more abundant and attained nuisance bloom proportions. Very low dissolved oxygen conditions have been observed regularly beginning in the late 1950s (Beeton 1969). Closely similar trends have been observed to varying degrees for all the other lakes except Lake Superior.

The chemical contents of all of the lakes except Lake Superior have also changed. The most dramatic chemical changes have occurred in Lake Erie, Lake Ontario, Saginaw Bay of Lake Huron, and Green Bay of Lake Michigan (Beeton 1969). The changes that have occurred are similar to those considered to be indices of cultural eutrophication (Hasler 1947). Also, many of the changes occurred at a time when nutrient enrichment of the lakes was accelerating. Consequently, the idea that the Great Lakes were undergoing measurable eutrophication was soon established and the popular press made many references to the "dead and dying" Lake Erie. Undoubtedly, a number of the changes were wholly, or at least partially, the consequence of the introduction of nutrients, especially phosphorus. Others were likely the result of pollu- tion by toxic substances and other contaminants. Nevertheless, the impacts of ecological factors, such as overfishing, introduction of exotic species, natural population cycles, changes in thermal conditions, and physical alterations, have had a role in these changes. These have not been adequately evaluated, however.

\section{Current Examples of Ecological Factors}

\section{Introduction or Invasion of Exotic Species}

Non-native or exotic organisms have had a major influence on the Great Lakes. In fact, the introduction of exotic species has caused, or at least exacerbated, some of the worst so-called pollution cases reported for the lakes. The alewife (Alosa pseudoharengus), sea lamprey (Petromyzon marinus), and white perch (Morone americana), all of which gained access to or spread within the lakes through canals such as the Welland, Erie, and New York Barge, have each caused changes in the Great Lakes that have been blamed on pollution. Moreover, the lakes have been very much affected through direct introduc- 
tions of a number of fish including rainbow trout (Salmo gairdneri), Pacific salmon (Oncorhynchus spp.), carp (Cyprinus carpio), and smelt (Osmerus mordax). Although their presence is less obvious, exotic organisms other than fish, such as the brackish-water plankter Eurytemora affinis, have also become established in and affected the ecology of the Great Lakes.

Sea lamprey. One of the best-known events leading to the degradation of the lakes, especially the upper lakes, was the invasion by the sea lamprey (Smith 1968). Sea lampreys gained access to the Great Lakes above Niagara Falls with the construction of the Welland Canal in 1829. As a result of their parasitic predation on large fish (Figure 2), the once abundant native populations of lake trout and other large fish such as burbot (Lota lota) were virtually eliminated from the upper lakes by the 1950's. Populations of whitefish (Coregonus clupeaformis) and the coregonid chubs (Coregonis spp.) also drastically declined as a result of sea lamprey predation. The loss of lake trout and whitefish was important not only because of their commercial and sport fishing value, but also because they helped maintain the natural balance among the fishes (as well as lower organisms) in the Great Lakes food chain.

Although the sea lamprey is now being controlled and lake trout restocking has been successful in restoring large populations of adult fish, natural reproduction by the stocked fish has been very limited. While it was at first suspected that toxic chemical contaminants, such as PCBs, were primarily responsible for reproductive failures, other factors are now thought to be important (Francis and others 1979). Of particular concern is the possibility that the genetic makeup of the stocked trout, which are mainly descendants of individuals taken from relatively small inland lakes, may preclude reproduction under the conditions occurring in the Great Lakes. Inappropriate numbers of and improper age distributions among stocked trout, interferences with survival of trout fry by other non-native fish species such as alewives and smelt, degradation of spawning reefs, and the inability of fish to find spawning areas as a result of stocking methods have also been cited as possible causes for reproductive failures (Magnuson and others 1980). Whatever the reasons, an expensive stocking program is presently required to maintain lake trout in the Great Lakes.

Ironically, some recent pollution control programs may have a negative effect on sea lamprey control. As a result of water quality improvements, some rivers formerly too polluted for sea lamprey spawning may now be suitable for such spawning. For example, a new wastewater treatment system in the Duluth/ Superior region of Lake Superior has vastly improved the chemical and biological quality of the lower reaches of the St. Louis River, the largest tributary to the United States portion of Lake Superior. Because of its size and vast areas suitable for

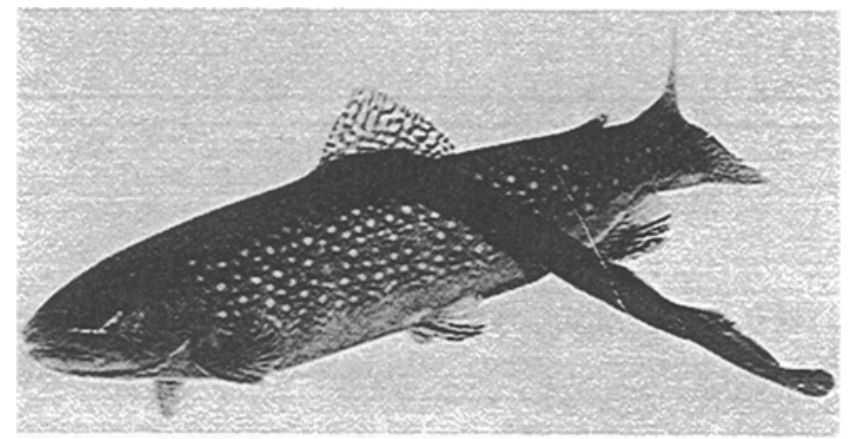

Figure 2. Sea lamprey predation on lake trout. Lamprey controls and lake trout stocking have been successful in restoring populations of adult lake trout in the upper lakes that were virtually eliminated by the parasite.

spawning, control of the sea lamprey in the St. Louis watershed will be difficult if cleaning up the lower reaches allows lampreys to reach spawning areas.

Alewife and smelt. Both alewife and smelt have proliferated in the Great Lakes. The alewife, in particular, has had a far-reaching effect on the ecosystem (Wells and McClain 1972). Massive alewife dieoffs in the 1960s marred recreational beaches (Figure 3) and fouled water supplies. Significan1 dieoffs of alewives and smelt have occurred as recently as the summer of 1980 . The accumulations of dead fish on beaches are very conspicuous to the public and are often blamed on pollution. However, the causes of the dieoffs are likely related to species overabundance (Colby 1971) and natural factors (for example, weather), although pollution can be an additional stress.

The dense populations of alewife and smelt also have contributed apparently to declines in native fishes such as coregonid chubs, yellow perch (Perca flavescens), walleyt (Stizostedion vitreum vitreum), and minnows (cyprinids). The alewives and smelt not only compete for the plankton forage of these fishes, but also may feed on their eggs and larvae. In fact Kohler and Ney (1980) maintain that alewife piscivority may have had a major effect on the collapse of certain nativt species.

Although not pollutants themselves, alewives apparently play a major role in transferring pollutants in the Great Lakes Weininger (1978) has concluded that alewives have a low fooc conversion efficiency. That is, they consume large quantities of pelagic organisms per unit of growth. Consequently, alewive: accumulate more contaminants, such as PCBs, associated witr pelagic forage, than fish with higher conversion efficiencies This may explain why lake trout in the upper Great Lakes, for which the alewife is the predominant forage, contain higk 


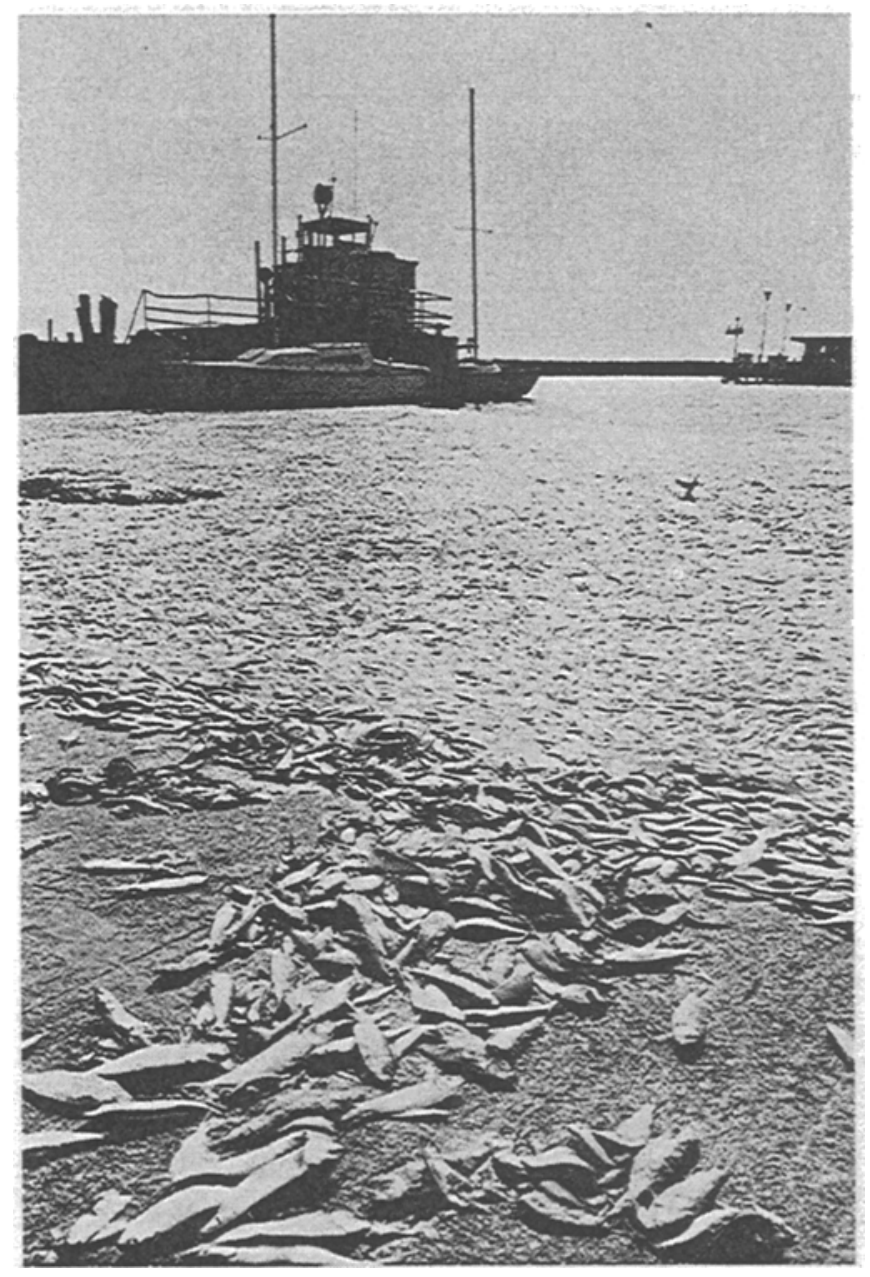

Figure 3. Great Lakes alewife dieoff. Scenes such as this were especially common during the 1960's. (Photo: Suzanne Tainter)

concentrations of PCBs and other contaminants. It also illustrates how ecological factors (that is, the introduction of exotic species) may influence the effect pollutant inputs have on the Great Lakes.

Salmonids. Historically, there have been numerous attempts to stock salmonids in the Great Lakes. Recently, however, a continuing program of stocking salmon has been initiated to crop overabundant alewives and smelt, as well as to provide sport fishing. The program has been very successful, especially from a sport fishing standpoint. However, several problems have developed. One is that large numbers of salmon die after spawning in Great Lakes tributaries. Decaying carcasses of large salmon have resulted in odor and aesthetic problems, particularly in the smaller, but numerous, branches of the main Great Lakes tributaries. Another problem is that the non-native salmonids may be competing with and causing the decline of desirable native species, such as brook trout (Salvelinus fontinalis), that occupy inland streams in the basin.

Carp. As in many lakes in North America, the Eurasian carp (Cyprinus carpio) has become established in the Great Lakes. Like the salmonids, they were apparently purposely introduced, although at an earlier date (late 1800s). Carp are thought to occupy the bottom feeding food niche formerly held by the lake sturgeon (Acipenser fulvescens), which was severely overfished (Francis and others 1979). Carp are believed to contribute to elevated turbidity levels by stirring up the bottom, particularly in shallow areas such as the western sector of Lake Erie. In such areas the increase in turbidity may be enough to have a negative influence on species inhabiting these waters, such as the pikes (Francis and others 1979), thus emphasizing that introduced species can have a major although relatively subtle effect on the ecosystem.

B. atropurpurea. The filamentous red alga, Bangia atropurpurea, is a recent addition to the Great Lakes, having first been reported in Lake Erie in the 1960s (Lin and Blum 1977). It has recently proliferated in Lake Michigan, at least in the southern two-thirds where suitable substrates for it to attach on exist. Lin and Blum (1977) reported that only a few filaments were noted along one Milwaukee breakwater in 1971, but that by 1974 it had grown to the extent that it gave a reddish color to the Milwaukee waterline.

Since $B$. atropurpurea is a halophilic organism, its recent proliferation has been linked to increased chloride (or possibly sodium) levels in the lakes (Stoermer 1980). This relation probably explains why its occurrence is restricted largely to harbor areas, for it is here that the major input of dissolved solids from point and nonpoint sources occurs.

The environmental effects of $B$. atropurpurea are not known; however, present growths in the Great Lakes are more extensive than anywhere in the world (Lin and Blum 1977). It does compete with native algae for suitable substrates, having largely displaced Ulothrix zonata in certain nearshore areas of Lake Michigan (Lin and Blum 1977). B. atropurpurea also appears to be displacing Cladophora in some locations (Stoermer 1980).

Perhaps most important, the reddish cast $B$. atropurpurea gives to nearshore waters is conspicuous to the public. The cast is easily confused with exotic chemical pollution. However, the presence of this organism, while probably not unrelated to chemical input to the lakes, is at least partially the result of subtle ecological factors.

Eurasian milfoil. Although not a problem in the Great Lakes themselves, the recent explosive spread of Eurasian 
milfoil (Myriophyllum spicatum) in inland lakes (including lakes in the Great Lakes basin) illustrates especially well that not all excessive plant growths are caused by pollution. Milfoil, native to Europe and Asia, is thought to have found its way to the United States in the late 1800s. The rooted plant grows aggressively, and can quickly choke shallow portions (1-6 m depth) of a lake. Concentrations of this plant make fishing difficult, snarl motors, and give off a "rotten eggs" smell when they die and decay. Its luxuriant growths are often believed by riparian owners and water users to be the result of pollution. However, there is no indication that this is the case. Its growth is not limited to lakes that are nutrient rich. In fact, it appears to have lower nutrient requirements than most other higher aquatic plants. Grace and Wetzel (1978) indicate that its anatomical features, growth form, and high vegetative reproductive capacity are responsible for its competitive success and wide distribution.

\section{Habitat Changes}

Pollution has been implicated as at least the partial cause of a number of ecologically significant habitat changes along the shores of, and in the tributaries to, the Great Lakes. However, there have also been a number of changes that are due to other causes such as dam-building and stream channelization, wetland destruction, shoreline modifications, dredging, and changes in land use within the basin.

For instance, the disappearance of the Atlantic salmon from Lake Ontario seems to have been caused by man-induced changes in the physical characteristics of the tributary streams used for spawning (Beeton 1969). Dams built on these streams when the Ontario basin was being settled may have been the most influential factor.

Excessive growths of Cladophora, filamentous green algae that can dislodge from its rocky substrate and collect on beaches, are generally considered one of the most unfavorable results of nutrient enrichment of the Great Lakes. However, in spite of abundant nutrients, Cladophora cannot grow without the proper rocky substrate (that is, habitat). Man has increased the amount of substrate suitable for Cladophora by placing breakwaters, rip rap, and other structures in the nearshore waters, although such artificially created substrates are probably a small proportion of the total. Water level changes may, in fact, be the most important factor influencing Cladophora growth. Both lower and higher water levels can result in significantly increased habitat suitable (both in terms of substrate and water depth) for Cladophora growth (Auer and Canale 1980, Moll and others 1979).

While the type of habitat available clearly has a major effect on organisms, the converse is also true, since biota can have a major effect on the environmental conditions that occur. For example, nymphs of the mayfly Hexagenia help to oxygenate sediments as a result of their burrowing. When conditions (for example, chemical pollution) occur that cause these organisms to be eliminated, which has happened in sections of Lake Erie, Green Bay, and Saginaw Bay, the sediment chemistry can be altered subsequently. This alteration can, in turn, affect the release or uptake of contaminants from sediments.

\section{Overfishing}

Reductions in fish stock have commonly been attributed to overfishing, although the effects of this stress often cannot be completely separated from those due to other stresses such as pollution. Unlike many of the other ecological factors, however, the significance of overfishing is generally understood by the public. The current controversy over Native American fishing rights in the upper Great Lakes is a case in point. Gill netting by Indian fishermen has been suspected of seriously depleting the numbers of lake trout in the upper lakes. The Michigan Department of Natural Resources has, in fact, lowered the sport fisherman's daily limit for lake trout. Since lake trout are basically maintained through stocking that is supported by sportsman license fees, the advisability of continued stocking has been questioned.

There is good evidence that overfishing was one of the primary factors that has affected the walleye (Stizostedion vitreum vitreum) population of Lake Erie. The walleye stocks essentially collapsed in the late 1950 's, probably due to a combination of limnological changes in the central basin, a population explosion of smelt, and overfishing (Regier and others 1969). Prior to the late 1940's most commercial fishing was by trap net. After 1948 and into the 1950's gill netting was permitted, especially in Canadian waters, and the effectiveness of capture is believed to have increased as much as 50 fold. Further, the 1953 through 1961 year classes of walleye grew much faster than the year classes from 1942 through 1952 (Parsons 1970), perhaps because of the effects of pollution during the 1950's and 1960's. This increase in growth rate resulted in a decrease in average age of fish taken in the commercial fishery from 2.6 years in 1942-1952 to 1.2 years in 1957-1961. Consequently, females that had not reached maturity (that is, age 3 years or older) were harvested, limiting reproduction.

Ironically, the walleye population was given a chance to recover from overfishing because of pollution, when in 1970 it was discovered that the walleyes were contaminated with mercury. This led to the closure of the fishery in Michigan, Ohio, and in Essex and Kent counties of the Province of Ontario (Baldwin and others 1979). Subsequently, the walleye was given sport fish status in Michigan in 1973 and in Ohio in 1974. In 1976, an interagency quota management system 
involving Ontario, as well as Ohio and Michigan, was implemented. Ontario has allocated a portion of its quota to the commercial fishery, but Michigan and Ohio have not. Thus although some commercial fishing still exists, walleye harvest has been reduced greatly and the walleye have made a strong comeback. In fact, walleye populations have become reestablished to the extent that Lake Erie is now a top choice for sportsmen seeking prime walleye fishing. While other factors, such as pollution abatement, may have played roles in the recovery of the walleye in Lake Erie, reduced harvesting has probably been the key to the recovery (Great Lakes Fishery Commission 1976).

A further example of overfishing is discussed by Jensen (1978), who attributes the collapse of the lake trout population in Lake Superior in the 1950s not only to predation by the sea lamprey (as is commonly cited), but also to overfishing. He maintains that at the time the lamprey were first observed in Lake Superior, commercial fishermen were moving into this lake from the other lakes where lake trout stocks were collapsing due to sea lamprey predation. Thus excessive exploitation may have stressed the Lake Superior population so that it was particularly sensitive to the lamprey.

\section{Natural Variations in Populations}

Although the preceding discussion has centered on maninfluenced ecological factors, natural processes, such as those caused by alterations in life history cycles, random population fluctuations, and disease, can also cause changes in the system. To illustrate, population sizes of plants and animals can vary greatly due to variations in the timing of natural reproductive cycles. Many of the larger bottom-dwelling invertebrates of the Great Lakes, such as worms, amphipods, and midge larvae, breed and reproduce on an annual cycle so that young are produced over a period of a few weeks once a year. The reproduction of certain fish species is timed to coincide with these invertebrates cycles. Consequently, slight variations in the timing of invertebrate and other life history cycles can have major ramifications throughout the ecosystem.

Random population fluctuations may also have a major effect on an ecosystem. For example, many plankton species have high growth and reproductive rates so they have a number of generations during a year, each of which is exposed to a quite different biological, chemical, and physical environment. These environmental differences have a great effect on rates of birth, mortality, and growth for the populations, and so they respond by undergoing large fluctuations in numbers. These population fluctuations may, in turn, affect populations of higher organisms, and thus cause ecosystem responses that are unrelated to pollution.

For species with the potential to live for a number of years, such as many of the fishes, reproduction and survival of young are much greater in certain years than in others. Eshenroder (1977) showed that between 1957 and 1975 the number of young yellow perch produced in Lake Huron during a year was strongly related to the rate and regularity of warming of the waters during spring. Years with regular and rapid warming tended to produce larger numbers of yellow perch, and so population levels were high immediately following such years. Hartman (1972) has shown a similar strong relation between reproductive success and spring temperatures for both walleye and yellow perch in Lake Erie.

Natural variations in populations may also be caused by disease and parasitism. While these conditions may be promoted by various stresses, such as pollution, they also occur naturally. For example, data from the English lake district indicate that parasitism by fungi may affect diatom populations (Lund 1950, Mortimer 1969). During one year, a greatly reduced spring bloom of Asterionella formosa was correlated with a severe fungal infestation. The parasitism was apparently unrelated to population and again demonstrates the importance of natural processes.

The general existence of strong natural fluctuations in the abundance of plant and animal species means one must be cautious in ascribing observed fluctuations to the effects of man's activities. Before pollution or other man-induced effects are blamed, the variability of the population in question due to natural factors should be taken into account to determine if the observed fluctuations or trends cannot be ascribed to these natural causes. Otherwise, large sums of money may be expended to "correct" ecosystem alterations that are actually due to natural causes.

\section{Eutrophication Effects Versus Ecological Changes}

Not recognizing ecological factors in Great Lakes management results partly from the often erroneous application of the concept of eutrophication to large lakes. For instance, the Great Lakes are frequently referred to as undergoing "premature aging" as a result of accelerated eutrophication (as in US Environmental Protection Agency 1980). Consequently, decision makers and the public in general frequently perceive the Great Lakes to be rapidly approaching a state that is similar to the small eutrophic inland lakes with which they are usually more familiar. Such a perception can lead to improper management and possibly the misdirected appropriation of large sums of money in the name of eutrophication control.

It is incorrect to expect the changes in the Great Lakes that are caused by eutrophication to be similar to those that have occurred in smaller lakes. Many of the changes observed in the Great Lakes that have been cited as evidence of eutrophication 
(often by limnologists most familiar with small lakes) may well be due, not to eutrophication, but to ecological factors (and possibly forms of pollution other than nutrients, such as toxic contaminants). As discussed by Beeton and Edmondson (1972), the classical concept of eutrophication (whereby nutrient enrichment stimulates growth of algae, favoring types such as blue-greens, and eventually causing loss of oxygen in the bottom waters and changes in the bottom sediments) cannot be applied to the Great Lakes. Their size and ecological diversity, as well as the conditions of morphometric oligotrophy found throughout the lakes except in some bays and in western and central Lake Erie, preclude any such overall response. Morphometric oligotrophy refers to the situation where, because of the great depth of the lake, much of the water is below the lighted zone where photosynthetic production can occur, and so nutrients are not fully utilized (Beeton 1965).

Part of the reason for the confusion in applying the concept of eutrophication to the Great Lakes stems from the historical development of this term. Early papers discussed eutrophication as an aspect of ecological succession, whereby all lakes started as oligotrophic and naturally matured into a eutrophic condition (Welch 1935). Sedimentation and reduction in depth (that is, filling of the lakes) were considered major factors in eutrophication. It was recognized that this natural process could be accelerated by runoff of nutrients from agricultural lands. Nevertheless, authors made a distinction between eutrophication, that is, the natural process of lake maturation, and artificial enrichment, either that due to intentional fertilization of water bodies or that caused by unintentional enrichment from municipal and industrial waste input. The distinction between natural and artificial eutrophication was diminished by Hasler (1947), who, in an often quoted paper, interpreted eutrophication to be lake enrichment by any and all nutritive substances regardless of source. According to Hasler's early work, nutrients have a cumulative effect, as he stated that there is "no way known at present for reversing the process of eutrophy."

The presently accepted concept is that eutrophication refers to natural or artificial addition of nutrients to bodies of water and to the effects of these nutrients (National Academy of Sciences 1969). This natural process can be greatly accelerated by man and, when the effects are undesirable, eutrophication has been considered a form of pollution. The effects of eutrophication are not necessarily the same in large lakes as in small lakes, however, and to state that the Great Lakes are "prematurely aging" or "filling up" is inappropriate. Further, there is no evidence to support the concept that natural eutrophication is a slow, gradual enrichment process affecting all lakes, large or small, throughout their existence (Beeton and Edmondson 1972). Various disruptions can occur in a drainage basin resulting in increased natural supplies of nutrients, but, as suggested by Hutchinson (1969), lakes can remain either oligotrophic or eutrophic systems through time.

Lake Erie is the only one of the Great Lakes whose morphometry is such that overall eutrophication effects are likely to be comparable to those observed in smaller lakes. Changes in the species composition and abundance of plankton usually associated with small-lake eutrophication have, in fact, taken place. Moreover, loss of oxygen in the bottom water has occurred with resultant changes in the sedimentary environment. Furthermore, most of the lake is shallow enough to that the altered sediments have affected chemical and biological conditions in the overlying waters.

However, even Lake Erie does not fully comply with the classical concept of eutrophication. Its eastern basin, because it is deeper than the rest of the lake, does not display many of the classical eutrophication symptoms. Further, Charlton (1980) has recently raised questions as to whether the rate of oxygen depletion in the hypolimnion of the central basin has actually increased during the past 60-80 years when Lake Erie supposedly experienced accelerated eutrophication. He contends that historical increases in hypolimnetic oxygen depletion in the central basin were more likely due to changes in hypolimnion thickness than to eutrophication. Year-to-year changes in hypolimnion thickness in Lake Erie are largely determined by meteorological forces, another important factor that, like ecological factors, is not related to pollution. Consequently, even in Lake Erie, the classic concept of eutrophication may only apply to portions of the lake. This is not to imply that nutrient enrichment has not caused serious pollution of Lake Erie and the other Great Lakes, but only that ecological and meteorological factors may be more responsible for observed changes than formerly believed.

\section{Possible Future Ecological Events}

From a planning context it is desirable to look ahead to possible future ecological events that could have a major effect on the Great Lakes ecosystem. Several possibilities are considered below.

\section{Crash of Alewife Population}

Because alewifes are a major food of lake trout and introduced salmonids in the Great Lakes, a sudden collapse of the population could have major ecological consequences. Excessive predation pressure by stocked salmonids plus a weak year class for alewives (due to chance factors such as weather effects on reproduction) might result in such a collapse. Similar population collapses have occurred with other forage fishes in both lake and ocean environments. A collapse of the alewife 


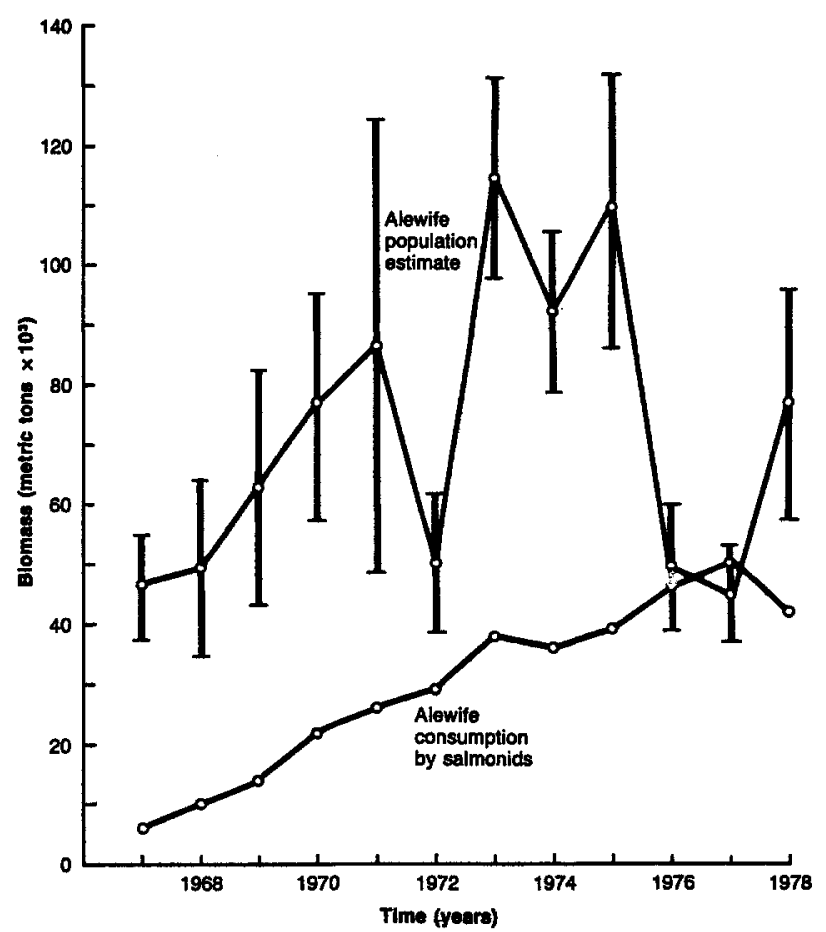

Figure 4. Estimated adult alewifes available to trawls (bars indicate $90 \%$ confidence limits) and estimated consumption of alewifes by salmonids from 1967-1978. Adopted from Hatch and others (1981) and Stewart and others (1981).

population in the Great Lakes would not only affect the valuable salmonid fishery, but could also change the abundance and distribution of other forage fish, such as the smelt, bloater (Coregonus hoyi), and sculpins (Cottus spp.)

The annual variability of adult alewife biomass between 1967 and 1978, based on adult alewife available to trawls, is illustrated in Figure 4. Although these estimates probably underestimate the total adult biomass, they do demonstrate considerable year-to-year changes in population size. Rising predation on alewives, as derived by Stewart and others (1981) based on steadily increasing salmonid stocking rates, is also shown in Figure 4. Since stocking rates are not responsive to alewife population fluctuations, Stewart and others contend that a major crash in the Lake Michigan alewife population may occur before any management action can be taken. Note that the estimated consumption of alewife in 1977 actually exceeds the estimated alewife biomass available to trawls. Similar situations, where accelerating stocking rates and natural population variations could cause a destabilization of predator-prey relationships, likely exist in Lake Huron and Lake Ontario.
The ecological consequences of an alewife collapse are also unclear. Whether fish such as the coho and chinook salmon could adapt to feeding on other forage fish and whether adequate levels of other forage are available to maintain the present populations of these salmon is not known. Stewart and others point out, however, that the decline of the alewife could have a beneficial aspect, as it might allow rehabilitation of some native species. Nevertheless, an alewife population crash is a possible future ecological event that deserves careful consideration from a management perspective.

\section{Explosion of Pink Salmon}

A small number of pink salmon (Oncorhynchus gorbudvhs) were inadvertently released in Lake Superior in 1956. By the late 1960's this species had become relatively abundant in the Lake (Lawrie 1978). They now enter tributaries all around the shores of the Lake Superior and have recently spread to Lake Huron and Lake Michigan.

Although little is known about their life history, the pink salmon appear to be pelagic and plankton feeders (Lawrie 1978). They do provide some sport for fishermen for a brief period when they first ascend streams during their spawning run at the end of their two-year life cycle. However, their small size (approximately $0.6 \mathrm{~kg}$ at maturity) and relatively poor eating quality, as well as their infrequent availability in streams, limit their sports fishery potential (Lawrie 1978, Wagner and Stauffer 1980).

Since both their abundance and distribution appear to be increasing, they may reach a level where they have an adverse competitive effect on other fishes or create a pollution problem in tributaries when they die after spawning. However, little is known as to how much they compete with other species for food or even whether they might serve as forage for larger salmonids. Lack of information notwithstanding, if they continue to spread and increase, they may reach a level where their abundance poses a serious problem for the ecological balance of the Great Lakes.

\section{Aquatic Plant Growth}

It is possible that macrophyte growth could increase in the future in certain shallow areas of the Great Lakes, such as western Lake Erie. Early recorded information (Trautman 1957) indicates western Lake Erie once had dense macrophyte populations. Possibly as a result of turbidity and siltation caused by clearing of the drainage basins as well as other ecological changes, these macrophyte populations have been decimated. However, it has been speculated that with improved pollution control and land management, environmental conditions could favor the return of dense macrophytic growths in the western basin. These growths would not necessarily be 
viewed favorably by all users of the resource. Such potential ecological changes need to be considered in lake management.

As discussed previously, the filamentous red alga, Bangia atropurpurea, has proliferated in parts of the Great Lakes. Stoermer (1980) reports that $B$. atropurpurea has expanded its range, and it appears to be adapting to a wider range of substrates than once thought suitable. In some areas it competes not only with Ulothrix zonata, but also with Cladophora glomerata. Although it is not yet possible to predict the impact of continued $B$. atropurpurea increases, it could be ecologically significant, since $C$. glomerata, although sometimes a nuisance, usually supports an appreciable epiphytic flora while $B$. atropurpurea does not.

\section{Overfishing}

As discussed earlier, overfishing has been a major factor affecting the biota of the Great Lakes, and will likely continue to be a factor in the future. Demands on the fish resource by sport, commercial, and Native American fisheries will cause problems for Great Lakes managers. Current controversy over the right of American Indians to fish unrestricted has been predicated on the belief that fish stocks could be seriously depleted by such action. Further, the Great Lakes Fishery Commission (1979) has asserted that unless exploitation by sport, commercial, and native fisheries is controlled, the success of the current program to restore self-sustaining populations of lake trout in suitable portions of the Great Lakes will be in doubt. There appears to be little question that if harvests continue to increase in the future, fish stocks could be seriously jeopardized. The carrying capacity of the resource is finite, despite the vast size of the Great Lakes. Past experiences in overexploitation of fish such as the walleye, lake herring, and sturgeon should serve as warnings for the future. As a case in point, the lake herring has not recovered from severe depletion in western Lake Superior and in other parts of the Great Lakes (Berg and others 1979).

\section{Modeling Ecological Effects}

Mathematical models provide a very promising means to quantify and predict environmental changes. Such models have recently received close attention for aiding in the solution of Great Lakes problems. However, the models developed to support Great Lakes decision making have been geared primarily toward pollution problems rather than ecological ones. An area of especially active model development to aid decision making has been in Great Lakes eutrophication control. A series of models for various areas in the Great Lakes has been developed that allows simulation (in various degrees of complexity) of the effects on the ecosystem of nutrient enrichment (for example Bierman and others 1980, Thomann and Segna 1980). The results from several models were compared and combined to form the primary basis for setting the phosphorus load objectives contained in the 1978 Water Quality Agreement between Canada and the United States (Bierman 1980). A few models concerned with pollution problems other than eutrophication, such as the cycling and effects of synthetic organics (for example, DDT, PCB's, Mirex), also have been or are being developed.

Models currently operational for management purposes, however, are not yet able to address ecological effects adequately, at least not the kind discussed in this paper. Basically this stems from two causes. First, the casual relations for many of the more important processes in Great Lakes ecosystems are still not understood, let alone quantitatively defined. Without the ability to do this in relation to an ecological impact, it is not possible to make accurate simulations or predictions concerning that impact. Secondly, many of the ecological impacts involve individual species or limited populations of a species. While some models consider such details, they are necessarily simplistic in the scope of the processes and relations which they can take into account. To model the detailed individual interactions and processes within an ecosystem as large as one of the Great Lakes would take an immense and very complex model. Although such models could conceivably be developed, it would be extremely expensive. Further, the great quantities of very complex output that would result would be difficult to interpret in ways that would fulfill management needs.

In short, modeling ecological relations, while promising, cannot be expected to meet the full needs of management in the foreseeable future. To be sure, current modeling efforts are leading to invaluable applications, such as providing assistance in efforts to separate ecological effects from those caused by man's activities. However, ecological model development should be looked at as only one of the tools available to aid management and one that needs much additional development before it reaches its full potential.

\section{Implications for Management}

In today's society greater emphasis than ever is placed on the economics of managing lakes, especially the Great Lakes, which are such a critical and valuable resource. For this reason, the role of ecological factors, such as the invasion of exotic species, habitat changes, effects of organisms on habitat, overfishing, and natural variations in populations of an organism, need to be carefully considered in a holistic and cost-effective approach to management.

The public must also be educated on the importance of ecological factors in causing changes in the Great Lakes and 
other lakes. They should realize, for example, that the tremendous resurgence in the walleye sport fishery in Lake Erie is not only the result of water quality improvement, but of ecological factors as well. They should understand that the Great Lakes are much different from the small inland lakes with which they are most familiar, and that the Great Lakes require different management strategies. They should be aware of the delicate balance among the organisms and of how future ecological events, such as a crash of the alewife population, could have far-reaching effects on the ecosystem. Oversimplifications, such as the popular reference to Lake Erie as being "dead" or the assertion that Lake Michigan is rapidly "aging," need to be replaced with an appreciation of the many factors that can affect an ecosystem. Further, these factors must be properly understood. Unfortunately, the current trend, at least in the United States, is one of decreasing emphasis for both Great Lakes research and management.

One of the difficulties in dealing with ecological factors in a management context is our inability to quantify their effects. Ecosystem models show promise in this regard, but their practical utility awaits further development. There is also a need to develop a better measure of how ecological factors may affect the outcome of different pollution management decisions. That is, in the future, managers will need to assess in quantitative terms the probability that proposed pollution control measures will result in the desired changes. Such risk analyses will require more consideration of how ecological factors (as well as other factors unrelated to pollution) could affect the outcome of management strategies.

Another important management consideration is the irreversibility of some ecological changes. For example, once a species of fish is eliminated or its numbers decimated, it may never recover. Even restocking may not be of value, since a specific genetic strain may be required for recovery.

Finally, perhaps one of the best ways to determine whether changes in the lakes are due to ecological effects or to pollution is to determine whether lakes actually respond to decreases in pollution. A unique situation currently exists in this regard for the Great Lakes, since major strides in pollution abatement have been carried out on these lakes over the last ten years. It is especially important that a careful evaluation of the effects on lake quality from current control measures be made. The importance of such an evaluation cannot be overemphasized. The multi-billion dollar efforts to control pollution in a water system as large as the Great Lakes are unprecedented, and the results will be closely watched throughout the world. A comprehensive and scientifically rigorous evaluation would provide much useful information to managers of the Great Lakes and other large lakes, including the relative importance of chemical pollution and ecological factors as a determinant of water quality.

\section{Acknowledgment}

This paper is Great Lakes Environmental Research Laboratory (National Oceanic and Atmospheric Administration) Contribution No. 270 and Great Lakes Research Division (University of Michigan) Contribution No. 310.

\section{Literature Cited}

Auer, M. T., and R. P. Canale. 1980. Phosphorus uptake dynamics as related to mathematical modeling of Cladophora at a site on Lake Huron. J. Great Lakes Res. 6:1-7.

Baldwin, N. S., R. S. Saalfeld, M. A. Ross, and H. J. Buettner. 1979. Commercial fish production in the Great Lakes 1867-1977. Great Lakes Fishery Commission Tech. Rept. No. 3. 187 pp.

Beeton, A. M. 1965. Eutrophication of the St. Lawrence Great Lakes. Limnol. Oceanogr. 10:240-254.

Beeton, A. M. 1969. Changes in the environment and biota of the Great Lakes. Pages 150-187 in Eutrophication: Causes, consequences, and correctives. Nat. Acad. Sci., Wash., DC.

Beeton, A. M.; and W. T. Edmondson. 1972. The eutrophication problem. J. Fish. Res. Board Canada. 29:673-682.

Berg, R., R. Eshenroder, and J. Kutkuhn. 1979. Third report of the ad hoc working group to assess stocks of lake trout, lake whitefish, chubs and lake herring in treaty waters of the upper Great Lakes-State of Michigan: Lake Superior. US Fish and Wildlife Service, Great Lakes Fisheries Laboratory, Ann Arbor, MI.

Bierman, V. J., Jr. 1980. A comparison of models developed for phosphorus management in the Great Lakes. Pages 235-255 in R. C. Loehr, C. S. Martin and W. Rast, eds. Phosphorus management strategies for lakes. Ann Arbor Science, Ann Arbor, MI.

Bierman, V. J., Jr., D. M. Dolan, E. F. Stoermer, J. E. Gannon, and V. E. Smith. 1980. The development and calibration of a spatially simplified multi-class phytoplankton model for Saginaw Bay, Lake Huron. Great Lakes Environmental Planning Study Contribution No. 33, Great Lakes Basin Commission, Ann Arbor, MI. 126 pp.

Charlton, M. N. 1980. Oxygen depletion in Lake Erie: Has there been any change? Can. J. Fish. Aquat. Sci. 37:72-81.

Colby, P. J. 1971. Alewife dieoffs: Why do they occur? Limnos 4:18-27.

Eshenroder, R. L. 1977. Effects of intensified fishing, species changes, and spring water temperatures on yellow perch, Perca flavescens, in Saginaw Bay. J Fish. Res. Board Can. 34:1830-1838.

Francis, G. R., J. J. Magnuson, H. A. Regier, and D. R. Talhelm. 1979. Rehabilitating Great Lakes ecosystems. Report to the Great Lakes Fisheries Commission. Ann Arbor, MI, 140 pp.

Grace, J. B., and R. G. Wetzel. 1978. The production biology of eurasian watermilfoil (Myriophyllum spicatum L.): A review. $J$. Aquat. Plant Manage. 16:1-22.

Great Lakes Fishery Commission. 1976. 1974 Annual Report. Ann Arbor, MI.

Great Lakes Fishery Commission. 1979. Correspondence from Commission Chairman to U.S. Secretary of State, dated 4 January. Ann Arbor, MI.

Hartman, W. L. 1972. Lake Erie: Effects of exploitation, environ- 
mental changes, and new species on the fishery resources. $J$. Fish. Res. Board Can. 29:899-912.

Hasler, A. D. 1947. Eutrophication of lakes by domestic drainage. Ecology 28:383-395.

Hatch, R. W., P. M. Haack, and E. H. Brown, Jr. 1981. Estimation of alewife biomass in Lake Michigan, 1967-1978. Trans. Amer. Fish. Soc. 110:575-584.

Hutchinson, G. E. 1969. Eutrophication, Past and Present. Pages 17-26 in Eutrophication: causes, consequences, correctives. Nat. Acad. Sci., Wash., DC.

Jensen, A. L. 1978. Assessment of the lake trout fishery in Lake Superior: 1929-1950. Trans. Amer. Fish. Soc. 107:543-549.

Kohler, C. C., and J. J. Ney. 1980. Piscivarity in a land-locked alewife (Alosa pseudoharengus) population. Can. J. Fish. Aquat. Sci. 37:1314-1317.

Lawrie, A. H. 1978. The fish community of Lake Superior. J. Great Lakes Res. 4:513-549.

Lin, C. K., and J. L. Blum. 1977. Recent invasion of a red alga (Bangia atropurpurea) in Lake Michigan. J. Fish. Res. Board Can. 34:2413-2416.

Lund, J. W. G. 1950. Studies on Asterionella formosa Hass II. Nutrient depletion and the spring maximum. J. Ecol. 38:1-35.

Magnuson, J. J., H. A. Regier, W. J. Christie, and W. C. Sonzogni. 1980. To rehabilitate and restore Great Lakes ecosystems. Pages 95-112 in J. Cairns, Jr. ed. The recovery process in damaged ecosystems. Ann Arbor Science, Ann Arbor, MI.

Moll, R., M. Brahce, E. T. Meriwether, E. Reyner, R. Snavely, and J. Mechling. 1979. The effects of water level regulation on water quality in Lake Erie. Great Lakes Research Division, University of Michigan, Ann Arbor, MI.

Morgan, C. A., and W. C. Sonzogni. 1980. Influence of water quantity on Great Lakes water quality. Great Lakes Environmental Planning Study Contribution No. 32, Great Lakes Basin Commission, Ann Arbor, MI. 38 pp.

Mortimer, C. H. 1969. Physical factors with bearing on eutrophication in lakes in general and in large lakes in particular. Pages 340-368 in Eutrophication: Causes, consequences, correctives. Nat. Acad. Sci., Wash., DC.

National Academy of Sciences. 1969. Introduction, summary, and recommendations. Pages 3-13 in Eutrophication: Causes, consequences, correctives. Nat. Acad. Sci., Wash., DC.

Parsons, J. W. 1970. Walleye fishery of Lake Erie in 1943-62 with emphasis on contributions of the 1942-61 year classes. J. Fish. Res. Board Can. 27:1475-1489.

Regier, H. A., V. C. Applegate, and R. A. Ryder. 1969. The ecology and management of the walleye in Western Lake Erie. Great Lakes Fishery Commission Tech. Rept. No. 15. 101 pp.

Smith, S. H. 1968. Species succession and fishery exploitation in the Great Lakes. J. Fish. Res. Board Can. 25:667-693.

Sonzogni, W. C. 1976. Weather and water quality. Great Lakes Communicator, 7(April):5-6.

Stewart, D. J., J. F. Kitchell, and L. B. Crowder. 1981. Forage fishes and their salmonid predators in Lake Michigan. Trans. Amer. Fish. Soc. 110:751-63.

Stoermer, E. F. 1980. Characteristics of benthic algal communities in the upper Great Lakes. EPA-600/3-80-073, U.S. Environmental Protection Agency, Environmental Research Laboratory, Duluth, MN. 73 pp.

Thomann, R. V., and J. S. Segna. 1980. Dynamic phytoplanktonphosphorus model of Lake Ontario: Ten-year verification and simulations. Pages 153-190 in R. C. Loehr, C. S. Martin, and W. Rast, eds. Phosphorus management strategies for lakes. Ann Arbor Science, Ann Arbor, MI.

Trautman, A. 1957. The fishes of Ohio. Ohio State University Press, Columbus. 683 pp.

US Environmental Protection Agency. 1980. Great Lakes. Environmental Midwest, April, pp. 12-14.

Wagner, W. C., and T. M. Stauffer. 1980. Three-year-old pink salmon in Lake Superior tributaries. Trans. Amer. Fish. Soc. 109:458-460.

Weininger; D. 1978. Accumulation of PCBs by lake trout in Lake Michigan. Ph.D. Thesis, University of Wiscorsin, Madison, WI.

Welch, P. S. 1935. Limnology. McGraw-Hill, NY. 471 pp.

Wells, L., and A. McClain, 1972. Lake Michigan: Effects of exploitation, introductions, and eutrophication on the salmonid community. J. Fish. Res. Board Can. 29:889-898. 